\title{
Modificação de técnica de preparo do plasma rico em plaquetas em cães
}

\section{Technique modification for platelet - rich plasma prepare in dogs}

\author{
Niara Vanat ${ }^{1 *}$; Thais Neris da Silva Medeiros ${ }^{1}$; Mara Regina Stipp Balarin ${ }^{2}$; \\ Patricia Mendes Pereira ${ }^{3}$; Fernando De Biasi ${ }^{4}$
}

\section{Resumo}

O plasma rico em plaquetas (PRP) possui diversos fatores de crescimento que auxiliam na regeneração tecidual. O presente trabalho tem como objetivo propor uma técnica para o preparo do PRP autólogo, por meio de um protocolo simples e rápido, obtido a partir de um volume pequeno de sangue total, que facilita a utilização em cães. Após a colheita de $8 \mathrm{ml}$ de sangue total, realizada em cinco cães, obtevese o PRP, de maneira asséptica, com uma concentração de plaquetas de duas a seis vezes maior que a contagem sérica inicial, com valores absolutos finais de 800.000 a $1.600 .000 / \mathrm{mm}^{3}$. A técnica pode ser realizada sem complicações, de maneira rápida, com poucos equipamentos, atingindo-se a concentração ideal das plaquetas e mantendo-se a esterilidade do plasma.

Palavras-chave: Plasma rico em plaquetas, regeneração tecidual, cão

\begin{abstract}
Platelet-rich plasma (PRP) has many growing factors that improve tissue regeneration. The goal of this paper is to describe an innovative, quick and simple technique for preparing autogenous PRP from a small amount of blood, which allowing use in dogs. After harvesting $8 \mathrm{ml}$ of total blood in five dogs, PRP was obtained using an aseptic technique, which rendered a platelet count two to six times more concentrated than the previous serum platelet count, with final absolute values between 800.000 and $1.600 .000 / \mathrm{mm}^{3}$. The technique can be developed quickly, without complications using simple equipments, reaching an ideal platelet concentration and keeping plasma sterility.
\end{abstract}

Key words: Platelet-rich plasma, tissue regeneration, dog

1 Pós-Graduanda do Dept ${ }^{\circ}$ de Medicina Veterinária Preventiva, Universidade Estadual de Londrina, UEL, Londrina, PR. E-mail: ni_vanat@yahoo.com.br; thaisnmedeiros@hotmail.com

2 Prof ${ }^{a}$ Dr $^{\mathrm{a}}$ Adjunta da Universidade Estadual de Londrina,UEL, Londrina, PR. E-mail: maravet@uel.br

3 Prof ${ }^{\mathrm{a}}$ Dr $^{\mathrm{a}}$ Adjunta do Dept ${ }^{\circ}$ de Clínicas Veterinárias, UEL, Londrina, PR. E-mail: pmendes@uel.br

4 Prof. Adjunto do Dept ${ }^{\mathrm{O}}$ de Clínicas Veterinárias, UEL, Londrina, PR. E-mail: biasi@uel.br

* Autor para correspondência 


\section{Introdução}

O plasma rico em plaquetas (PRP) é um gel rico em proteínas e serve como uma fonte de fatores de crescimento (FCs), que são armazenados em grânulos no interior das plaquetas. Estes fatores auxiliam nos processos de mitose, quimiotaxia, diferenciação, crescimento das células mesenquimatosas pluripotenciais e produzem a matriz extracelular, atuando na regeneração dos tecidos (VIEGAS et al., 2006).

O PRP é utilizado em vários segmentos da odontologia (para reconstrução de maxilas e mandíbula) (AGHALLO; MOY; FREYMILLER, 2002; 2005; NUNES FILHO et al., 2007; LU et al., 2008), medicina humana e veterinária, como por exemplo, em transplantes de córnea (LUENGO GIMENO et al., 2006), cicatrização de feridas com diabetes mellitus (DRIVER et al., 2006) e regeneração óssea.

Existem dois tipos de PRP: autólogo e alógeno. O autólogo diminui a transmissão de doenças infecto-contagiosas e as reações imunológicas por rejeição (MARX et al., 1998; VIEGAS et al., 2006; SCHMIDT, 2003). As plaquetas alógenas podem se tornar inviáveis, não secretando os fatores de crescimento ativos, além de conter fatores de antigenicidade (MARX, 2004).

A concentração de plaquetas no PRP para fins terapêuticos deve ser significativamente maior que a concentração plasmática para proporcionar a liberação adequada de FCs no local da aplicação (PAGLIOSA; ALVES, 2007). O PRP é obtido pela centrifugação do sangue total através do gradiente de densidade, obtendo-se uma grande concentração de plaquetas em um pequeno volume de plasma (MARX et al., 1998; FROUM et al., 2002; FREYMILLER; AGHALOO, 2004; MARX, 2004). No coágulo sanguíneo normal, 95\% das células são hemácias, $5 \%$ plaquetas e menos de $1 \%$ de células brancas. No PRP, esse quociente entre hemácias e plaquetas é invertido (BARBOSA et al., 2008; ROSSI JUNIOR, 2001). Segundo Lemos,
Rossi Junior e Píspico (2002), um PRP adequado deve conter no mínimo 1.000.000 de plaquetas por micro-litro de plasma.

Os fatores limitantes para a utilização do procedimento são: presença de trombocitopenia ou de inviabilidade (lise celular) em que os FCs podem ser liberados antes do tempo (MARX, 2004; BARBOSA et al., 2008; DUSSE et al., 2008; KASTEN et al., 2008). O preparo do PRP deve ser cuidadoso e de modo asséptico para evitar a contaminação. Para conseguir uma consistência melhor e facilitar a aplicação do gel, pode ser adicionado a íons cálcio, trombina autóloga bovina ou osso biparticulado (DUSSE et al., 2008).

Várias técnicas são citadas na literatura para o preparo do PRP, tendo sido padronizada pela primeira vez na odontologia por Marx et al. (1998). Os autores coletaram 400 a $450 \mathrm{ml}$ de sangue humano com citrato fosfato dextrose (razão 1:5), por meio de um aparelho de separação de células por gradiente de densidade. Os autores centrifugaram o sangue a $5600 \mathrm{rpm}$, havendo a separação do plasma sobrenadante pobre em plaquetas (PPP), a zona de névoa (PRP) e as células vermelhas no fundo do tubo. Foi retirado o plasma sobrenadante e o restante (zona de névoa e células vermelhas), foi novamente centrifugado com uma rotação de 2400 rpm para separação do PRP das células vermelhas. As mesmas com o plasma sobrenadante foram reinoculadas no paciente e após isso, adicionouse 10.000 unidades de trombina bovina ao PRP. O procedimento de preparo durou aproximadamente 20 a 30 minutos entre a colheita e a aplicação. As concentrações plaquetárias iniciais variaram de 111.000 a $523.000 \mathrm{~mm}^{3}$ e após o procedimento de 595.000 a $1.100 .000 \mathrm{~mm}^{3}$.

Rossi Junior (2001) coletou 40mL de sangue divididos em seis a oito tubos de vácuo contendo citrato de sódio, que foram centrifugados a $800 \mathrm{rpm}$ por $10 \mathrm{~min}$. As hemácias precipitaram na porção final do tubo e o PRP com leucócitos formaram um sobrenadante. O PRP foi pipetado e armazenado em 
outros dois tubos adicionados de $0,5 \mathrm{~mL}$ da zona de névoa. Os tubos foram centrifugados novamente a $1300 \mathrm{rpm}$ por $10 \mathrm{~min}$. Retirou-se $2 \mathrm{~mL}$ do plasma sobrenadante e deixou-se $2 \mathrm{~mL}$ com o botão plaquetário, formado no fundo do tubo. Agitouse levemente e no momento do uso adicionou-se trombina autóloga bovina e gluconato de cálcio.

Aghallo, Moy e Freymiller (2002) utilizaram $10 \mathrm{~mL}$ de sangue obtidos de coelhos, adicionados a $1.1 \mathrm{~mL}$ de anticoagulante citrato fosfato dextrose. Centrifugaram a $1500 \mathrm{rpm}$ por $10 \mathrm{~min}$. O plasma sobrenadante foi retirado e misturado com $0,4 \mathrm{~mL}$ do mesmo anticoagulante inicial e centrifugaram por $3000 \mathrm{rpm} / 10 \mathrm{~min}$. O plasma pobre em plaquetas foi separado do PRP pela zona de névoa. Esses dois últimos foram ressuspendidos e adicionados a 5000 unidades de trombina autóloga bovina, reconstituída com cloreto de cálcio a $10 \%$. A contagem inicial de plaquetas variou de 70.000 a $260.000 / \mathrm{mm}^{3}$, e após o preparo do PRP, variou de 625.000 a $1.495 .000 / \mathrm{mm}^{3}$.

Lemos, Rossi Junior e Píspico (2002) utilizaram 13,5 mL de sangue de cães separados em três tubos de 4,5 mL com citrato de sódio. Os tubos foram centrifugados a $750 \mathrm{rpm}$ por $10 \mathrm{~min}$. O PRP de cada tubo foi pipetado e acondicionado em outro tubo, obtendo-se $3 \mathrm{~mL}$. Posteriormente, $1 \mathrm{~mL}$ da zona de névoa foi pipetada e armazenada em outro tubo. No momento do uso, foi adicionado ao PRP obtido $(1,5 \mathrm{~mL}) 1 \mathrm{~mL}$ de cloreto de cálcio a $10 \%$ e trombina bovina tópica (10.000UI). O número de plaquetas $/ \mathrm{mL}$ encontrado variou de 1.000 .000 a $1.200 .000 / \mathrm{mm}^{3}$.

Choi et al. (2004) coletaram $45 \mathrm{~mL}$ de sangue de cães e centrifugaram a $5600 \mathrm{rpm}$, havendo a separação do plasma sobrenadante (PPP), a zona de névoa (PRP) e as células vermelhas no fundo do tubo. Foi retirado o plasma sobrenadante e o restante (zona de névoa e células vermelhas), foi novamente centrifugado com uma rotação de 2400rpm para separação do PRP das células vermelhas. Adicionou-se a $1 \mathrm{~mL}$ do PRP com $1 \mathrm{~mm}$ de células vermelhas, ativados com solução a $10 \%$ de cloreto de cálcio, 5.000 unidades de trombina autóloga bovina. As concentrações plaquetárias do PRP variaram de 910.000 a $1.804 .000 \mathrm{~mm}^{3}$.

Oyama et al. (2004) coletaram 40mL de sangue de humanos separados em 4 tubos de $10 \mathrm{~mL}$ contendo citrato fosfato dextrose adenosina. Centrifugaram os tubos a $160 \mathrm{~g}$ por $20 \mathrm{~min}$. A porção sobrenadante e a camada inferior foram colhidas e centrifugadas novamente a $400 \mathrm{~g}$ por $15 \mathrm{~min}$. Parte do sobrenadante foi removido e o restante era o PRP.

Driver et al. (2006) estudaram um protocolo de preparo de PRP autólogo em 129 pacientes humanos com úlceras podais. Coletaram $20 \mathrm{~mL}$ de sangue e centrifugaram por 1,5 min para separação do PRP das células vermelhas. O PRP foi extraído por meio de uma seringa contendo reagentes para ativação do gel e utilizado em seguida.

Viegas et al. (2006) obtiveram $5 \mathrm{~mL}$ de sangue venoso da veia jugular de ovelhas e de cães, em tubos de amostras sanguíneas com $1 \mathrm{~mL}$ de fosfato citrato dextrose de sódio. Centrifugaram a amostra por $5600 \mathrm{rpm}$ por $10 \mathrm{~min}$. Desprezou-se $2 \mathrm{~mL}$ do plasma sobrenadante e realizou-se uma segunda centrifugação a $2400 \mathrm{rpm}$ por $15 \mathrm{~min}$, obtendo-se 1 a $2 \mathrm{~mL}$ de PRP. No momento do uso, adicionouse $0,5 \mathrm{~mL}$ de cloreto de cálcio a $10 \%$ com 10000 unidades de trombina tópica de origem bovina e 0,5 $\mathrm{mL}$ de ar, onde foram agitados em uma seringa para utilização.

Nunes Filho et al. (2007) coletaram 20mL de sangue de cães adicionados a 3,8\% de citrato de sódio. Centrifugaram a $1200 \mathrm{rpm}$ por 8 a 10 min até a separação em três camadas: PRP (sobrenadante), PRP (camada intermediária) e hemácias (camada inferior). Após a obtenção do PRP, ativaram-no com cloreto de cálcio a $10 \%$

Silva et al. (2007a) utilizaram $12 \mathrm{~mL}$ de sangue venoso da jugular com anticoagulante citrato de sódio, de oito cães adultos de pequeno e médio porte. O sangue foi separado em 4 tubos com 3 $\mathrm{mL}$ cada, centrifugados a $1000 \mathrm{rpm}$ por $10 \mathrm{~min}$. 
O plasma sobrenadante e a zona de névoa foram transferidos para dois tubos estéreis e realizouse uma segunda centrifugação a $1500 \mathrm{rpm}$ por 10 min. Foram descartados $2 / 3$ do sobrenadante e homogeneizado 1/3 restante, obtendo-se o PRP. Para utilização, adicionou-se trombina cálcica ao PRP e a hidroxipatita 20\%. As concentrações plaquetárias obtidas variaram de 275.000 a $1.145 .000 \mathrm{~mm}^{3}$.

Barbosa et al. (2008) coletaram $18 \mathrm{~mL}$ de sangue da jugular de três cães de grande porte. Utilizaram citrato de sódio como anticoagulante, centrifugando a $1300 \mathrm{rpm}$ por $8 \mathrm{~min}$. Após a retirada do plasma sobrenadante, o mesmo foi aliquotado em outro tubo e centrifugado, utilizando-se o mesmo tempo e velocidade anteriores. Obteve-se $0,5 \mathrm{~mL}$ de PRP e no momento do uso, adicionou-se Soluplastin ${ }^{\circledR}$. A contagem plaquetária inicial variou de 244.000 a $418.000 \mathrm{~mm}^{3}$ e após o procedimento de $1.512 .032 \mathrm{a}$ $2.590 .2850 \mathrm{~mm}^{3}$.

Lu et al. (2008) coletaram 60mL de sangue venoso de humanos em tubos contendo citrato dextrose. Centrifugou-se a $200 \mathrm{~g}$ por $15 \mathrm{~min}$. O plasma sobrenadante e a zona de névoa foram recolhidos e centrifugados novamente na mesma velocidade por $10 \mathrm{~min}$. Após descarte do plasma pobre em plaquetas, a parte inferior do plasma e o botão de plaquetas foram ressuspendidos e utilizados como PRP. A contagem de plaquetas variou de 500.000 a 1.000 .000 plaquetas $/ \mu \mathrm{L}$.

Silva et al. (2009) coletaram $9 \mathrm{~mL}$ de sangue do plexo venoso retro orbital de coelhos. O sangue foi colhido em tubos à vácuo $(4,5 \mathrm{~mL})$ com citrato de sódio. Os tubos foram centrifugados a $1300 \mathrm{rpm}$ por $12 \mathrm{~min}$. Em uma capela de fluxo laminar, o plasma sobrenadante foi retirado, restando as hemácias no fundo do tubo e a zona de névoa. Foram pipetados $25 \mu \mathrm{L}$ da zona de névoa por tubo e reservados em outro tubo. Uma nova centrifugação do plasma foi realizada a $1300 \mathrm{rpm}$ por $8 \mathrm{~min}$, identificando-se um botão de plaquetas no fundo dos tubos. Foi retirado o plasma sobrenadante, restando $125 \mu \mathrm{L}$ de plasma e botão de plaquetas. Adicionou-se $25 \mu \mathrm{L}$ da zona de névoa, obtendo-se o PRP final. No momento do uso, foram adicinados $75 \mu \mathrm{L}$ de Soluplastin ${ }^{\circledR}$. A contagem de plaquetas no PRP foi superior a $1.000 .000 / \mathrm{mm}^{3}$.

Muitos procedimentos clínicos necessitam a utilização do PRP em cães, tornando-se justificável a padronização de uma técnica que utilize um pequeno volume de sangue e que seja de fácil execução, mantendo a esterilidade do plasma rico em plaquetas.

\section{Material e Métodos}

Foram colhidas amostras de sangue de cinco da Universidade Estadual de Londrina (UEL), aproveitando-se o mesmo ato da colheita para os exames de rotina (solicitados pelos médicos veterinários). Por meio da venopunção da jugular externa dos animais, obteve-se $8 \mathrm{~mL}$ de sangue divididos em dois tubos comerciais com citrato de sódio (1:9) (Petrovacuum $®)$, com 4 mL cada. Logo após a colheita, as amostras foram encaminhadas para o laboratório de patologia clínica da mesma instituição para o preparo do PRP.

No laboratório, as amostras foram homogeneizadas e centrifugadas em baixa rotação (1500 rpm) por 10 minutos. Após a centrifugação do tubo contendo citrato de sódio e sangue total, ocorreu a separação da amostra em três camadas. O sedimento com hemácias e leucócitos; a camada intermediária de hemácias (zona de névoa), alguns leucócitos e plaquetas maiores; e o sobrenadante composto por plasma com plaquetas (Figura 1). 
Figura 1. Plasma sobrenadante, zona de névoa e hemácias sedimentadas após primeira centrifugação.

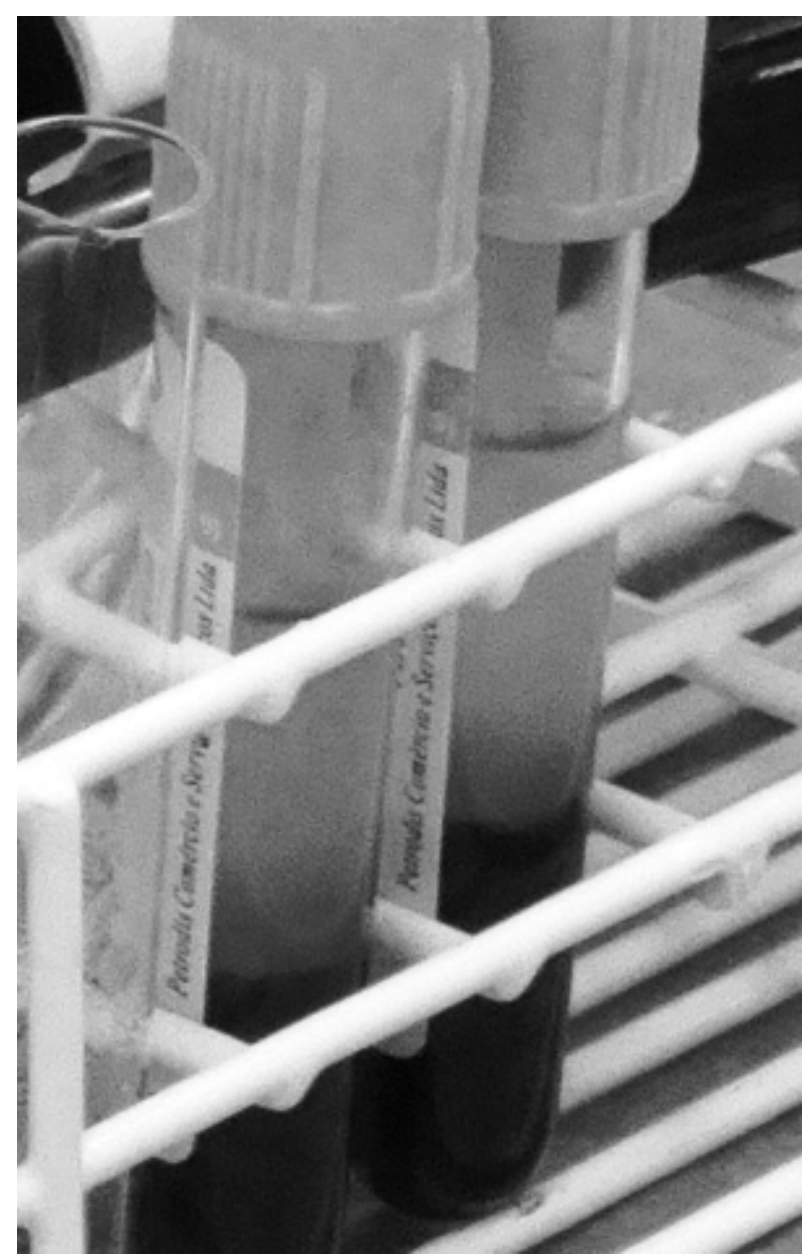

Fonte: Elaboração dos autores.

O plasma sobrenadante dos dois tubos foi pipetado e separado em apenas um tubo de hemólise estéril de vidro $(12 \times 75 \mathrm{~mm})$. Separadamente, $200 \mu \mathrm{L}$ da zona de névoa de cada tubo foi aliquotada em outro tubo de hemólise estéril, totalizando $400 \mu \mathrm{L}$. O frasco contendo o plasma sobrenadante foi centrifugado em baixa rotação (1500 rpm) por 10 minutos observando-se um botão de plaquetas no fundo do tubo (Figura 2). Retirou-se o sobrenadante deixando $450 \mu \mathrm{L}$ (plasma e botão), com volume previamente demarcado no tubo de hemólise. Aos $450 \mu \mathrm{L}$, adicionou-se $50 \mu \mathrm{L}$ da zona de névoa, homogeneizando-se levemente, obtendo-se $500 \mu \mathrm{L}$ de plasma rico em plaquetas.
Simulando-se o momento da utilização, foi adicionado ao PRP $25 \mu \mathrm{L}$ de Soluplastin ${ }^{\circledR}$, formando uma massa de consistência gelatinosa e avermelhada (Figura 3).

A amostra foi processada em até 30 minutos após a colheita de sangue do paciente. Os materiais utilizados, tais como as ponteiras e tubos de hemólise de vidro $(12 \times 75 \mathrm{~mm})$, foram esterilizados em autoclave e a amostra foi processada próxima a um bico de bunsen. Para garantir que nesse procedimento não houvesse risco de contaminação, foram realizadas culturas dos PRP produzidos, não havendo crescimento bacteriano em nenhum dos cinco casos. $\mathrm{O}$ meio de cultura utilizado foi o aguar sangue a $20 \%$, mantidos em estufa a $37^{\circ} \mathrm{C}$ por até sete dias.

Figura 2. Formação do botão de plaquetas após segunda centrifugação.

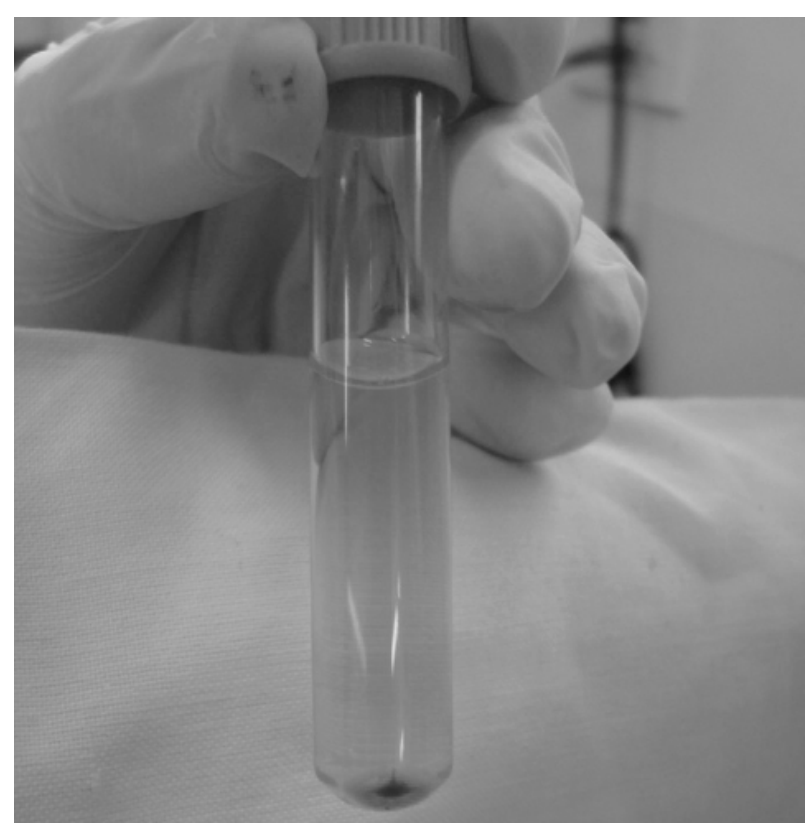

Fonte: Elaboração dos autores. 
Figura 3. Gel rico em plaquetas.

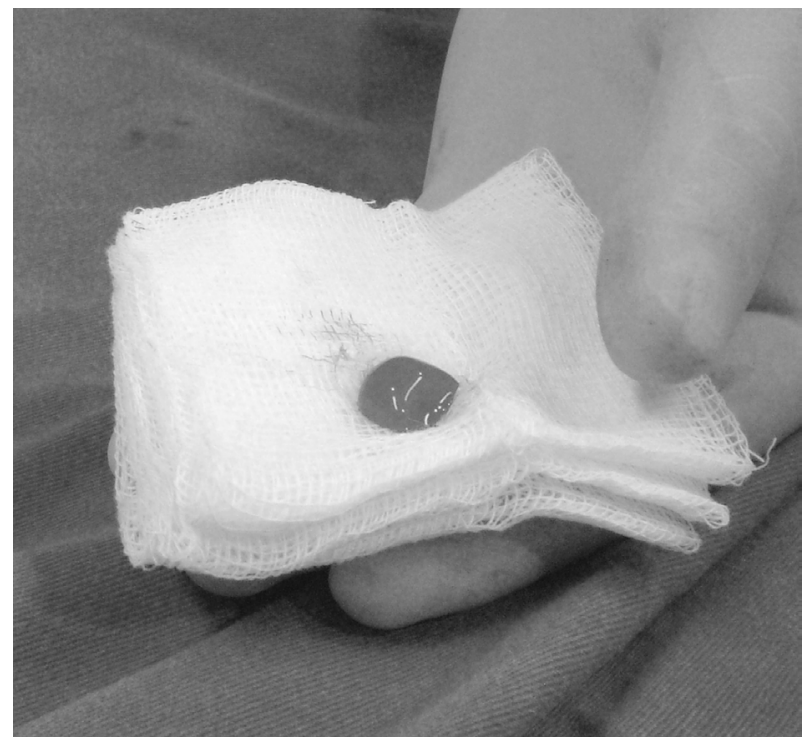

Fonte: Elaboração dos autores.

Para a contagem de plaquetas, realizou-se um esfregaço do PRP corado com Panótico ${ }^{\circledR}$. Ao microscópio com objetiva de imersão, foi estimado o número de plaquetas totais contando-se cinco campos homogêneos e multiplicando a média dos campos por 15000 , obtendo-se o número total em $\mathrm{mm}^{3}$ (SILVA et al., 2007b). Esta mesma contagem de plaquetas foi procedida no hemograma inicial e foi comparada com a contagem final do PRP.

\section{Resultados e Discussão}

O sangue obtido para confecção do PRP foi colhido em frascos com o anticoagulante citrato de sódio, seguindo-se o protocolo proposto por Barbosa et al. (2008); porém são citados na literatura outros anticoagulantes como: solução de citrato dextrose (LU et al., 2008), citrato dextrose ácido (SÁNCHEZ et al., 2005), citrato fosfato dextrose e adenosina (OYAMA et al., 2004), citrato fosfato dextrose (AGHALLO; MOY; FREYMILLER, 2005), citrato (PAGLIOSA; ALVES, 2007) e heparina (KASTEN et al., 2008). A escolha do citrato de sódio, neste trabalho, foi pela facilidade de obtenção, já disponível de forma estéril no frasco, diminuindo a possibilidade de contaminação no momento da colheita.

A técnica descrita neste trabalho destaca algumas vantagens com relação à quantidade da amostra utilizada. $\mathrm{O}$ volume sanguíneo colhido $(8 \mathrm{~mL})$ é diferente de outros autores que variam de 12 a 45 $\mathrm{mL}$, otimizando a técnica e o uso do plasma rico em plaquetas autólogo em cães (SILVA et al., 2007a; CHOI et al., 2004). Viegas et al. (2006) utilizaram um volume pequeno de sangue inicial $(5 \mathrm{~mL})$ em cães, porém não citaram a concentração final das plaquetas. Em humanos, é descrito a utilização de um volume sanguíneo maior para produção do PRP, variando de $20 \mathrm{~mL}$ a $450 \mathrm{~mL}$ que é proporcional ao tamanho do indivíduo e ao tamanho da lesão tecidual (DRIVER et al., 2006; MARX, 2004).

Neste protocolo, são realizadas duas centrifugações de 1500rpm, com duração de 10 minutos cada, estando de acordo com autores como Choi et al. (2004); Silva et al. (2007a); Pagliosa e Alves (2007), que utilizaram duas centrifugações de 1000 a $5600 \mathrm{rpm}$ e tempo de 6 a 15 minutos (CONSOLO et al., 2007; LUENGO GIMENO et al., 2006). Diferentemente de outros autores que utilizam apenas uma centrifugação com variação de velocidade, entre 1200 a 8000 rpm (LEMOS; ROSSI JUNIOR; PÍSPICO, 2002; NUNES FILHO et al., 2007), optou-se por utilizar uma rotação de 1500 rpm. Segundo Ferraz, Ferrigno e Schmaedecke (2007), centrifugações variando de 1300 a 1600 rpm não causaram alterações morfológicas graves nas plaquetas; no entanto, quando utilizadas rotações de $3200 \mathrm{rpm}$, obteve-se uma alta contagem na concentração de plaquetas obtidas em relação ao plasma, porém as mesmas apresentaram lesões consideráveis. Isto pode acarretar prejuízo na liberação dos fatores de crescimento necessários para o reparo tecidual.

Para obtenção do gel de PRP, foi adicionado Soluplastin ${ }^{\circledR}$, assim como nos trabalhos de Barbosa et al. (2008) e Silva et al. (2009), para promover adesão e facilitar a aplicação no local de lesão 
tecidual. Outros autores utilizaram trombina bovina a $100 \mathrm{U} / \mathrm{ml}$ com cloreto de cálcio a $10 \%$ (inibe a ação do anti-coagulante ativando o PRP), cloridrato de cálcio a $10 \%$, gluconato de cálcio a $10 \%$, fibrina humana e hidroxiapatita. (MARX et al., 1998; AGHALLO; MOY; FREYMILLER, 2002; LEMOS; ROSSI JUNIOR;PÍSPICO, 2002; CHOI et al., 2004; OYAMA et al., 2004; LUENGO GIMENO et al., 2006; WILSON; BARBIERI; MAZZER, 2006; VENDRAMIN et al., 2006; CONSOLO et al., 2007; NUNES FILHO, 2007; PAGLIOSA; ALVES, 2007). Optou-se por utilizar o Soluplastin ${ }^{\circledR}$, ao invés de outras substâncias porque há uma facilidade de obtenção comercial quando comparado por exemplo a trombina bovina, que é mais dificilmente encontrada no Brasil (BARBOSA et al., 2008), além de já conter comercialmente a associação com cloreto de cálcio, cloreto de sódio e tromboplastina (SILVA et al., 2009).

No presente trabalho, obteve-se uma concentração de plaquetas 2 a 6 vezes maior que o total da contagem sérica inicial, estando dentro do encontrado por Gonshor (2002) e Kevy e Jacobson (2004), que foi de 3 a 5 vezes. Além disso, o número de plaquetas concentradas variou de 800.000 a $1.600 .000 / \mathrm{mm}^{3}$, que segundo Marx (2004), está de acordo com a quantidade ideal para um plasma rico em plaquetas.

A concentração ideal de plaquetas obtidas na presente técnica foi possível mesmo com um volume pequeno de sangue inicial. Isto possibilitaria a utilização do PRP autólogo que oferece vantagem ao PRP heterólogo, como citado por Kasten et al. (2008). Além disso, este protocolo foi de fácil realização, sendo executado num período de tempo semelhante ao citado por Marx et al. (1998), de 20 a $30 \mathrm{~min}$.

Os resultados negativos das culturas microbianas do PRP, ao final do procedimento, evidencia que a técnica asséptica durante a colheita e o preparo foi eficaz, mesmo sem o fluxo laminar, o qual foi utilizado em outros trabalhos (SILVA et al., 2009).

\section{Conclusão}

A técnica de preparo do PRP proposta neste trabalho utiliza equipamentos disponíveis na maioria dos hospitais veterinários que dispõem de laboratório clínico. Tem como vantagens a facilidade e rapidez de execução e mantêm a esterilidade do plasma. Além disso, é eficaz em obter uma concentração ideal de plaquetas e pode ser utilizado a partir de um menor volume de sangue que facilita o uso do PRP autólogo em cães.

\section{Fontes de aquisição}

Petrovacuum ${ }^{\circledR}$

Importador: Petrodis Comércio e Serviços Técnicos, Ltda

Rua Johann Dupré 625, Petrópolis, RJ, Brasil

Soluplastin ${ }^{\circledR}$

Elaborado por/Manufactured by: Wierner Laboratórios S.A.I.C.

Riobamba 2944

2000 Rosario - Argentina

www.wierner-lab.com.ar

Panótico®

Newprov Produtos Para Laboratório

www.newprov.com.br

\section{Referências}

AGHALlO, T. L.; MOY, P. K.; FREYMILLER, E. G. Evaluation of platelet-rich plasma in combination with freese-dried bone in rabbit cranium. A pilot study. Clinical Oral Implants Research, Copenhagen, v. 16, n. 2, p. 250-257, 2005.

Investigation of platelet - rich plasma in rabbit cranium defects. A pilot study. Journal of Oral and Maxillofacial Surgery, Philadelphia, v. 60, n. 10, p. 11761181, 2002.

BARBOSA, A. L. T.; DEL CARLO, R. J.; GOMES, H. C.; OLIVEIRA, A. C.; MONTEIRO, B. S.; DEL CARLO, B. N. Plasma rico em plaquetas para reparação 
de falhas ósseas em cães. Ciência Rural, Santa Maria, v. 38, n. 5, p. 1335-1340, 2008.

CHOI, B. H.; IM, C. J.; HUH, J. Y.; SUH, J. J.; LEE, S. $\mathrm{H}$. Effect of platelet - rich plasma on bone regeneration in autogeous bone graft. International Journal of Oral and Maxillofacial Surgery, Copenhagen, v. 33, n. 1, p. 56-59, 2004.

CONSOLO, U.; ZAFFE, D.; BERTOLDI, C.; CECCHERELLI, G. Platelet - rich plasma activity on maxillary sinus floor augmentation by autologous bone. Clinical Oral Implants Research, Copenhagen, v. 18, n. 2, p. 252-262, 2007.

DRIVER, V. R.; HANFT, J.; FYLLING, C. P.; BERIOU, J. M. A prospective, randomized, controlled trial of autologous platelet - rich plasma gel for treatment of diabetic foot ulcers. Ostomy Wound Management, King of Prussia, Pensilvania, v. 52, n. 6, p. 68-87, 2006.

DUSSE, L. M. S.; MACEDO, A. P.; BATSCHAUER, A. P.; CARVALHO, M. G. Plasma rico em plaquetas (PRP) e sua aplicação em odontologia. Revista Brasileira de Análises Clínicas, Rio de Janeiro, v. 40, n. 3, p. 193-197, 2008.

FERRAZ, V. C. M.; FERRIGNO, C. R. A.; SCHMAEDECKE, A. Platelet concentration of plateletrich plasma from dogs, obtained through three centrifugation speeds. Brazilian Journal of Veterinary Research and Animal Science, São Paulo, v. 44, n. 6, p. 435-440, 2007.

FREYMILLER, E. G.; AGHALOO, T. L. Platelet-rich plasma: ready or not? Journal of Oral and Maxillofacial Surgery, Philadelphia, v. 62, n. 4, p. 484-488, 2004.

FROUM, S. J.; WALLACE, S. S.; TARNOW, D. P.; $\mathrm{CHO}$, S. C. Effect of platelet - rich plasma on bone growth and osseointegration in human maxillary sinus grafts: three bilateral case reports. The International Journal of Periodontics Restorative Dentistry, Chicago, v. 22, n. 1, p. 45-53, 2002.

GONSHOR, A. Technique for producing platelet-rich plasma e platelet concentrate: background and process. The International Journal of Periodontics Restorative Dentistry, Chicago, v. 22, n. 6, p. 547-557, 2002.

KASTEN, P.; VOGEL, J.; GEIGER, F.; NIEMEYER, P.; LUGINBÜHL, R.; SZALAV, K. The effect of plateletrich plasma on healing in critical-size long-bone defects. Biomaterials, Guildford, v. 29, n. 29, p. 3983-3992, 2008.

KEVY, S. V.; JACOBSON, M. S. Comparison of methods for point of care preparation of autologous platelet gel. Journal of ExtraCorporeal Technology, Bloomsburg, v. 36, n. 1, p. 28-35, 2004.
LEMOS, J. J.; ROSSI JUNIOR, R.; PÍSPICO, R. Utilização de plasma rico em plaquetas em enxertos ósseos - proposta de um protocolo de obtenção simplificado. 2002. Disponível em: <http://www. odontologia.com.br/artigos.asp? $\mathrm{id}=225>$. Acesso em: 31 mar. 2009.

LU, H. H.; VO, J. M.; CHIN, H. S.; LIN, J.; COZIN, M.; TSAY, R.; EISIG, S.; LANDESBERG, R. Controlled delivery of platelet - rich plasma - derived growth factors for bone formation. Journal of Biomedical Materials Research. Part A, Hoboken, v. 86, n. 4, p. 1128-1136, 2008.

LUENGO GIMENO, F.; GATTO, S.; FERRO, J.; CROXATTO, J. O.; GAllO, J. E. Preparation of Platelet-rich plasma as a tissue adhesive for experimental transplantation in rabbits. Thrombosis Journal, v. 4, n. 1, p. 18, 2006. Disponível em: <httpp://www. thrombosisjournal.com/content/4/1/18>. Acesso em: 31 mar. 2009.

MARX, E. Platelet-rich plasma: evidence to support its use. Journal of Oral and Maxillofacial Surgery, Philadelphia, v. 62, n. 4, p. 489-496, 2004.

MARX, R. E.; CARLSON, E. R.; EICHSTAEDT, R. M.; SCHIMMELE, S. R.; STRAUSS, J. E.; GEORGEFF, K. R. Platelet-rich plasma: grow factor enhancement for bone grafts. Oral Surgery, Oral Medicine, Oral Pathology, Oral Radiology \& Edodontics, Saint Louis, v. 85, n. 6, p. 638-646, 1998.

NUNES FILHO, D. P.; LUPPINO, F.; YAEDÚ, R. Y. F.; CARVALHO, P. S. P. Avaliação microscópica da ação do osso autógeno associado ou não ao PRP em cavidades ósseas de cães. Revista Implantnews, São Paulo, v. 4, n. 3, p. 263-269, 2007.

OYAMA, T.; NISHIMOTO, S.; TSUGAWA, T.; SHIMIZU, F. Efficacy of platelet-rich plasma in alveolar bone grafting. Journal of Oral and Maxillofacial Surgery, Philadelphia, v. 62, n. 5, p. 555-558, 2004.

PAGLiOSA, G. M.; ALVES, G. E. S. Considerações sobre a obtenção e o uso do plasma rico em plaquetas e das células mesenquimais indiferenciadas em enxertos ósseos. Ciência Rural, Santa Maria, v. 37, n. 4, p. $1202-$ 1205, 2007.

ROSSIJUNIOR, R. Protocolo simplificado para obtenção de PRP. 2001. Disponível em: <http://www. plaquetas. net/tecnicas.html\#Protocolo $\% 20$ somplificado $\% 20$ para $\% 20$ obtenção $\% 20$ de $\% 20$ deP.R.P>. Acesso em: 20 maio 2009.

SÁNCHEZ, A. R.; ECKERT, S. E.; SHERIDAN, P. J.; WEAVER, A. L. Influence of platelet-rich plasma added to Xenogeneic bone grafts on bone mineral density 
associated with dental implants. International Journal of Oral and Maxillofacial Implants, Lombard, v. 20, n. 4, p. 526-532, 2005.

\section{SCHMIDT, A. H. Symphony ${ }^{\mathrm{TM}}$ PCS (Platelet Concentrate} System) in tibial bone grafting: a report of three cases. In: SYMPHONY (Ed.). Carolina Blood Management, Inc, 2003. Disponível em: <http://www. carolinabloodmgt. com/PDF\%20Files/symphony_pcs.pdf $>$. Acesso em: 20 maio 2009.

SILVA, P. F. N.; BALARIN, M. R. S.; MARUCHI, H. P.; FLAIBAN, K. K. M. C.; MOROZ, L. R. M. Correlação entre o hemocitômetro e outras técnicas de rotina para a contagem do número de plaquetas em cães atendidos no Hospital Veterinário da Universidade Estadual de Londrina (H.V.-UEL). Semina: Ciências Agrárias, Londrina, v. 28, n. 4, p. 659-664, 2007b.

SILVA, P. S.A ; DEL CARLO, R. J.; SERAKIDES, R.; MONTEIRO, B. S.; BALBINOT, P. Z.; ELEOTÉIO, R. B.; PAEZ, O. L. A.; VILORIA, M. I. V. Plasma rico em plaquetas associado ou não ao osso esponjoso autógeno no reparo de falhas ósseas experimentais. Ciência Rural, Santa Maria, v. 39, n. 1, p. 129-134, 2009.

SILVA, S. B.; FERRIGNO, C. R. A.; STERMAN, F. A.; BACCARIN, D. C. B.; YAZBEK, K. V. B.; MURAMOTO, C.; AMAKU, M. Plasma rico em plaquetas combinado a hidroxiapatita na formação do calo ósseo em fraturas induzidas experimentalmente no rádio de cães. Ciência Rural, Santa Maria, v. 37, n. 4, p. 1045-1051, 2007a.

VENDRAMIN, F. S.; FRANCO, D.; NOGUEIRA, C. M.; PEREIRA, M. S.; FRANCO, T. R. Plasma rico em plaquetas e fatores de crescimento: técnica de preparo e utilização em cirurgia plástica. Revista do Colégio Brasileiro de Cirurgiões, Rio de Janeiro, v. 33, n. 1, p. 24-28, 2006.

VIEGAS, C. A. A.; DIAS, J. M.; AZEVEDO, J. M. T.; FERREIRA, A. J.; SAN ROMÁN, F.; CABRITA, A. M. S. A utilização de Plasma rico em plaquetas na regeneração do tecido ósseo alveolar e cortical. Estudos experimentais num modelo de defeito ósseo periodontal em cão Beagle (Canis familiaris) e num modelo de defeito ósseo cortical na ovelha (Ovies aries). Revista Portuguesa de Ciências Veterinárias, v. 101, n. 559-560, p. 193-213, 2006.

WILSON, E. M. K.; BARBIERI, C. H.; MAZZER, N. Estimulação da cicatrização óssea pelo plasma autógeno rico em plaquetas. Estudo experimental em coelhos. Acta Ortopédica Brasileira, São Paulo, v. 14, n. 4, p. 208-212, 2006. 
